\title{
Adolescentes, Professores e Psicanalistas: uma intervenção clínicopolítica
}

\author{
Joana Sampaio Primo' \\ Miriam Debieux Rosa' \\ Viviani Carmo-Huerta"
}

'Universidade de São Paulo (USP), São Paulo/SP - Brasil

"Université Paris Ouest Nanterre, Paris - França

RESUMO - Adolescentes, Professores e Psicanalistas: uma intervenção clínicopolítica. O que fazem psicanalistas nas escolas? Esse artigo, debate uma intervenção psicanalítica clínicopolítica na escola, que interpela adolescentes e equipe de ensino a constituir e partilhar seus saberes. Distinguimos três tempos na intervenção em que pudemos constatar o sofrimento dos adolescentes quando as funções da escola estão atravessadas pelo recorte da raça e da classe, atravessamento que se concretiza na correlação entre desenvolvimento, pobreza, raça e perigo social. Quando os saberes puderam circular em diálogo pode-se localizar os conflitos e o mal-estar da escola diante da adolescência e das complexidades da situação histórico-social brasileira, de modo a tornar a construção dos conflitos como motor de trabalho e não como fracasso das equipes.

Palavras-chave: Psicanálise. Intervenção Clínico-Política. Adolescência. Escola. Conflito.

ABSTRACT - Adolescents, Teachers, and Psychoanalysts: a clinical political intervention. What do psychoanalysts do in schools? This article discusses a clinical-political psychoanalytic intervention at school that interpellates teenagers and the teaching staff into constituting and sharing their knowledge. During the intervention, three moments are distinguished at which we could assert the suffering of adolescents when the school's functions are cross-cut by race and class, a crossing mimicked in the correlation among development, poverty, race, and social danger. When knowledge could be shared through dialogue, the school's conflicts and discomfort vis-à-vis adolescence and the complexities of the Brazilian historical-social situation could be located, thereby highlighting the establishment of conflicts as engines of work rather than as failure of the teaching staff.

Keywords: Psychoanalysis. Clinical-Political Interventions. Adolescence. School. Conflict. 
Adolescentes, Professores e Psicanalistas

\section{Introdução}

A ligação entre o campo educacional e o campo psi é quase tão antiga quanto o estabelecimento da escola moderna como modelo de educação dos Estados nacionais. As modalidades desse tipo de interação, no entanto, passam por diversas polêmicas quanto à sua ética e às suas implicações, tema que requer um debate que vai além dos limites deste artigo. Destacamos que uma prática constante em que esses campos do conhecimento atuavam conjuntamente era para classificar aqueles que fugiam aos padrões comportamentais ou de aprendizagem esperados, produzindo diagnósticos e discursos para determinar quem ficaria fora da escola ou naturalizando a evasão escolar. Um modo de os saberes psi se colocarem no interior de escolas seria como aqueles que detém um saber sobre os desvios que poderiam responder aos anseios imediatos das equipes. Todavia, acreditamos que operar dessa forma com o saber potencializa o saber de mestria - imposto ao outro, tal como descrito por Lacan (1992) —, rechaçando os princípios éticos da psicanálise, pautados pela escuta dos sujeitos e da trama institucional.

A recente problematização trazida pelo ensino inclusivo e pela psicologia institucional, que passa a debruçar-se sobre as dinâmicas da escola enquanto instituição, possibilita outra modalidade de relação entre esses saberes, criando outros modos dos saberes psi circularem nas escolas. Nesse contexto, o presente artigo discute o que fazem os psicanalistas nas escolas, problematizando as condições e possibilidades éticas de se sustentar uma escuta do sujeito em instituições de ensino.

Este artigo em particular é fruto de questões da pesquisadora Joana Sampaio Primo, que coordena o acompanhamento da escolarização de crianças imigrantes ou filhas de pais imigrantes, em algumas escolas de um determinado bairro de São Paulo, pesquisa ligada ao Laboratório de Psicanálise Sociedade e Política (PSOPOL $\left.{ }^{1}\right)$. É do interior dessa intervenção que surgiu a proposta de fazer um grupo com adolescentes em uma das unidades de ensino que acompanhamos. A oferta de fazer grupos de conversa com os adolescentes foi uma proposição construída em diálogo com a coordenação dessa escola, fundamental para o desenvolvimento de nosso trabalho e das ideias aqui contidas².

A aposta de nosso trabalho, nomeado de intervenção psicanalítica clinicopolítica, parte do princípio de que a escuta, em contextos de vulnerabilidade social, implica que o psicanalista, necessariamente, lance mão de estratégias clínicas não convencionais, promovendo uma psicanálise implicada, pois atenta à complexidade histórica e social de sua formulação (Rosa, 2016). Uma escuta que, ao levar em conta o contexto institucional, complexifica suas estratégias ao propor não só a escuta dos sujeitos, mas o retorno de seu saber como algo que diz de todos. Fazemos questão de sublinhar que nos compreendemos participando desse nós institucional: partilhamos a mesma história, fazemos parte da mesma cidade e nos encontramos no mesmo campo de trabalho. 
Em linhas gerais, pretendíamos “[...] criar a possibilidade de o adolescente encontrar um Outro receptivo e disposto a lhe fornecer um Outro saber, não fechado" (Catroli; Rosa, 2013, p.310), que pudesse constituir com os jovens um espaço de circulação da palavra, no qual o saber pudesse ser construído a partir de suas incongruências e não de certezas imaginárias. Dito de outro modo, chegamos com uma aposta na escuta como um lugar de reconhecimento do sujeito. Sujeito dividido, saber carregado de incoerências e fissuras, mas justamente por isso, capaz de sustentar conflitos, estes que podem na escuta, por suas voltas e reviravoltas, possibilitar que o sujeito venha a "[...] se posicionar de outra forma diante daquilo que o determina” (Sousa, 2000, p. 18).

Tratando-se de uma escuta situada numa instituição, percebemos a importância de esse saber poder ganhar um lugar institucional, num gesto ético de produção de enigmas que dizem respeito ao coletivo e não somente aos indivíduos diretamente envolvidos na escuta. Entendemos que os conflitos são sempre internos e externos, ou seja, perpassam os sujeitos e o coletivo, uma vez que a noção dicotômica entre indivíduo e sociedade é questionada pela psicanálise. Dessa forma, além dos grupos de conversa, identificamos a necessidade de circulação do saber produzido pelos adolescentes à escola, retorno combinado com o grupo de estudantes e que, a nosso ver, colaborou para a dimensão construtiva dos conflitos (Vicentin; Gramkow, 2018), de forma a arrefecer os lugares predestinados à adolescência, ao desvio e ao conflito.

Sendo algo próprio da posição adolescente em nosso tempo, isto é, uma determinada supervalorização concomitante a uma desvalorização, os adolescentes passam muito rapidamente de um ideal de pura felicidade para um ideal de pura violência (Rosa, 2011), o que desponta como um período de conflitos. Fase discriminada, majoritariamente, como uma etapa do desenvolvimento humano, necessita, todavia, ser contextualizada historicamente como um período intrínseco à modernidade, uma vez que a ideia de desenvolvimento surge com os saberes e práticas que se construíram em torno da figura do anormal (Foucault, 2014).

Apesar de entendida principalmente como uma etapa do desenvolvimento, orientamo-nos, no presente artigo, em sentido contrário. Apoiadas pela concepção psicanalítica de adolescência, nós a concebemos como um momento "[...] de destituição e constituição da ficção fantasmática que passará a orientar o sujeito no mundo” (Catroli; Rosa, 2013, p.298; Rosa; Huerta, 2020). Dessa forma, afirmamos a adolescência como o momento em que os sujeitos são confrontados com o sexual, ou seja, com a impossibilidade de um encontro pleno com o Outro, impossibilidade que os remete aos limites da castração. Momento, portanto, de passagem da cena familiar para a cena social, atravessamento não óbvio e carregado pela complexidade histórico-social que marca todos os sujeitos, porém distintamente, a depender da posição que ocupam no laço. Desse modo, os processos dos adolescentes diante dos dilemas humanos relativos à sexualidade, morte, pertença e transformação social contam a sua própria história, mas dizem também sobre o modo 
Adolescentes, Professores e Psicanalistas

como cada sociedade concebe as modalidades de inscrição do sujeito no laço social, assim como sua disponibilidade às transformações sociais (Rosa, 2011; Rosa; Huerta, 2020).

Por se configurar como num tempo de passagem, a adolescência pode ser localizada entre deixar de ser criança e vir a ser adulto, processo em que os adolescentes convocam o tecido social para um movimento de báscula entre abertura e fechamento: abertura, uma vez que os conflitos os extrapolam; fechamento, porque rapidamente são lidos como uma questão do adolescente. É justamente por ocuparem uma posição de indagação da ordem social, incluída aí a escola, que apontamos o princípio ético que nos orienta, a saber, pressupor que os adolescentes carregam um saber que deve interpelar a todos, sobretudo, em contextos institucionais. Em outras palavras, abrir espaço para questões adolescentes significa apostar na produção do saber não todo, em um saber que se faz conjuntamente, num saber que abre espaço para o conflito.

Orientadas, portanto, pelo saber que interpela o saber do mestre, distinguimos três tempos em nossa intervenção clinicopolítica em escolas, em alusão ao tempo lógico lacaniano (Lacan, 1998): no primeiro, o instante de ver, deparamo-nos com a apresentação das psicanalistas ${ }^{3}$ para a escola e para os adolescentes sobre o que fazem psicanalistas nessas instituições. No segundo, tempo para compreender, os conflitos pedem passagem, isto é, começam a ser construídos na escuta dos grupos de conversa cotejados pelos problemas do laço social que os atravessam: as particularidades da escola como uma instituição do Estado moderno, em específico o caso brasileiro, atrelada ao desdobramento dos conceitos de desenvolvimento, adolescência e desvio. Faz parte, ainda, do tempo de compreender, debater nossa concepção de adolescência que tenta fazer frente aos discursos desenvolvimentistas e segregacionista sobre a mesma. Por fim, momento de concluir, quando os discursos dos adolescentes retornam como um saber da instituição que, junto com os dos professores, podem construir as coordenadas dos conflitos que recolocam as forças em jogo e distribuem as responsabilidades.

Para dar conta de tentar transmitir aquilo que se produziu no encontro com esses jovens e o pensamento decorrente das questões adolescentes que nos interpelaram e que puderam interpelar a instituição, optamos por organizar nosso texto em fragmentos. Fragmentos, porque concebemos o caráter fragmentário da realidade, podendo encontrar “[...] sua unidade ao buscá-la através dessas fraturas, e não ao aplainar a realidade fraturada” (Adorno, 2012, p. 35). Trabalho, portanto, de caráter ensaístico, isto é, que utiliza a forma ensaio como uma maneira própria de produzir pensamentos, maneira que não reduz seu objeto, mas, ao contrário, amalgama-se com ele, faz jus a suas complexidades, incompletudes e seus despropósitos (Adorno, 2012). Ademais, a escolha por fragmentos, além de afirmar o caráter incompleto da realidade, tenta tensionar a divisão sujeito-objeto própria de qualquer investigação. Inspiradas pelos autores que já citamos, pela importância de os saberes poderem circular nas instituições e, sobretudo, pela importância de o pesquisador se ver implicado com aquilo que produz, elegemos 
os fragmentos. Seus cortes e recortes pressupõem uma mão hesitante e pensante (Sousa, 2000), isto é, cortes que compõem e recompõem o caminho da produção de um saber fragmentário.

\title{
Tempos da Escuta Clinicopolítica: intervenção em contexto escolar - 10 Tempo - Momento de Apresentação: o que fazem psicanalistas nas escolas?
}

\begin{abstract}
Fragmento 1: Psicólogo, para mim, é frescura!
Era nosso primeiro contato com esses jovens, estávamos no horário do intervalo, dispostas a escutá-los depois de haver nos apresentando como psicólogas que iriam fazer um grupo de conversa, semanal, com quem desejasse. Eles se apresentaram: contaram histórias familiares, histórias de cortes, de depressão e de namoros. Paramos em uma roda de conversa no pátio, eles nos indagaram: "[...] não, vocês não vão querer escutar essa música, tem muito palavrão", fala um garoto de um grupo de jovens que escutavam música com fone de ouvido. Continuam na conversa, querendo entender melhor quem nós éramos, indagam, provocam: “[...] psicólogo para mim éfrescura"; outra complementa "[...] minha mãe também é psicóloga, nos bate com uma régua de madeira". Afastamo-nos um pouco, entramos em outra roda, esta apenas de meninas. Aí a conversa, também curiosa com a nossa presença, nos interroga mais diretamente: "Quantos anos você tem?", "É casada?", “Tem filhos?", "Nossa, você é igual à Xuxa!". Referência que nos remete a nossa condição de brancas, com olhos claros e cabelo castanho. Isso num primeiro momento foi escutado com grande estranhamento, "Xuxa, eu?", ganhou o estatuto do estranhamento-familiar: ser branca com olhos claros num grupo de jovens negras é uma marca que precisa ser destacada.
\end{abstract}

A apresentação pede passagem: motivadas por nossa presença, por nosso primeiro encontro, a força das perguntas e provocações marcam a presença do/a adolescente. Um misto de provocação e curiosidade, amalgamadas com o lugar em que estávamos e com as diferenças sociais que nos atravessavam. Talvez, se não estivéssemos na escola, eles não se importariam com os palavrões da música? Talvez, se não vivêssemos numa sociedade marcada pelo dinheiro como um valor, valor que se espalha nas classes e nos conceitos de raça, não iríamos parecer com a Xuxa (artista brasileira loira e de olhos azuis)?

Assim, o primeiro tempo é o tempo das indagações, indagações que pedem pensamentos, reflexão e história: quem éramos nós e quem eram eles nessa cena, marcada por uma história? Faz-se necessário, portanto, situar o campo da educação e da adolescência.

É em busca de começar o cotejamento de pensamentos que os fragmentos convocam, que indicamos a função paradoxal que a educação cumpre: ela pode ser o instrumento a partir do qual todo indivíduo pode ou não ter acesso a qualquer tipo de discurso. Isto é, todo sistema de educação é "[...] uma maneira política de manter ou de modificar a apropriação dos discursos, com os saberes e os poderes que eles trazem consigo" (Foucault, 2001, p. 44). Não obstante, a escola cumprir uma função social de manutenção dos discursos que compõem os Estados nacionais, ela, paradoxalmente, pode funcionar como uma instituição 
Adolescentes, Professores e Psicanalistas

que também promove a modificação dos discursos e das práticas mais corriqueiras de nossa sociedade.

Sem apostar ingenuamente na educação como a salvação de nossa sociedade, justamente por compreendermos toda a complexidade histórica de sua formação e todos os discursos e práticas cotidianas que a sustentam, acreditamos que dar visibilidade aos conflitos escolares pode possibilitar um gesto crítico, isto é, possibilitar tornar os gestos fáceis demais em gestos difíceis (Foucault, 2010).

Entendemos por conflito aquilo que advém de um complexo jogo de forças entre práticas e saberes, forças que estão sempre em movimento. Entretanto, elas não são imediatamente apreensíveis; aquilo que nomeamos como conflito, geralmente brigas, são cenas conflitivas que, quando aparecem, tomam grande intensidade, muitas vezes na forma totalizadora da violência. Tornar os conflitos visíveis, a despeito dos "[...] simples confrontos de interesse ou simples bloqueios institucionais" (Foucault, 2010, p. 357), significa empreender uma construção do conflito (Vicentin; Gramkow, 2018). Esta provoca uma análise das implicações das forças que estão em jogo, podendo, a partir de então, expor que aquilo que nos constitui é mais ligado a: "[...] mais contingências do que necessidades, a mais arbitrariedades do que evidências, a mais contingências históricas complexas mas passageiras do que a constantes antropológicas inevitáveis" (Foucault, 2010, p. 357).

Conflito também é uma noção central na psicanálise, na qual o jogo de forças pode ser localizado entre as exigências pulsionais e a exigências impostas pela realidade externa. Freud (2018) chega a localizálo como a irremediável luta a qual todos estão condenados e pela qual surge o Eu como uma instância precipitada desse conflito, que, todavia, nunca deixará de existir: "O êxito foi alcançado à custa de uma fissura no Eu que não se curará jamais, e que aumentará com o tempo. A função sintética do Eu, de importância tão extraordinária, tem condições particulares e está sujeita a uma série de distúrbios" (p. 347).

Assim, aquilo que é a síntese de como nos reconhecemos e somos reconhecidos socialmente tem fissuras, fissuras irremediáveis, formadas por conflitos que podem ser entendidos como motores de criação.

É evidente que há diferenças entre a concepção foucaultiana e a freudiana de conflito, porém tomamos ambas no que tange pensar as relações institucionais nas quais nos colocamos e os sujeitos com os quais ali trabalhamos. Tal concepção nos permite ir de encontro à invisibilidade dos conflitos gerados no e pelo laço social que, quando recai sobre o sujeito, individualiza seus impasses, patologiza ou criminaliza suas saídas (Rosa et al., 2019). Como vimos, quando se trata de adolescentes a tendência de serem calados aumenta, justamente, por estarem implicados em marcar de maneira inédita a cena social, já que passam da cena familiar para a cena social, passagem que pode ter um efeito de denúncia das forças mais elementares de nossos gestos.

Finalizamos o tempo de ver, sublinhando aquilo que escolhemos para nos apresentarmos: uma indagação vinda da interpelação dos es- 
tudantes - Quem nós éramos? Do que gostamos? Falamos palavrão? que nos fez introduzir os princípios éticos e políticos que nos norteiam, ressaltando a dimensão da construção do conflito como basilar em qualquer trabalho em escola.

\section{2o Tempo - Momento de Compreender: o conflito pede passagem e construção}

\section{Escola, Desvio e o Anormal: breves apontamentos sobre a história da escola no Brasil e sua articulação com o conceito de desenvolvimento}

Da mesma forma como o instante de ver terminou com o questionamento: Quem éramos nós naquela cena?, iniciamos o tempo de compreender com a seguinte indagação: O que de nosso tecido social latejava naquela apresentação: a psicologia, a raça, a classe, a adolescência elou a escola. Perguntas que pulsam em nosso cotidiano, mas que nem sempre queremos ver. Pulsam porque marcam fronteiras de trânsito, de saber e de práticas. É exatamente na direção de podermos nos situar nessa cena através dos muitos atravessamentos que a estabelece que compreendemos a necessidade de nos voltarmos às concepções basilares que a conformam: os saberes que constituem os campos psi e o conceito de desenvolvimento; a formação das escolas no Estado brasileiro, e o imbricamento da produção da adolescência num Estado no qual o desvio marcará indiscriminadamente a maioria da população.

Partimos, então, a partir do fragmento de apresentação, para as linhas de força que o constituem, por entendermos que "Assim como é difícil pensar o meramente factual sem o conceito, porque pensá-lo significa sempre já concebê-lo, tampouco é possível pensar o mais puro dos conceitos sem alguma referência à facticidade" (Adorno, 2012, p. 26), isto é, intentamos produzir um jogo tenso entre os fragmentos e a história dos conceitos que os compõem.

Pretendemos, como sugere Foucault (2000), realizar um trabalho que se situe na fronteira entre uma análise histórica das condições de fortalecimento de determinados discursos e as suas materializações nas práticas cotidianas (Primo; Rosa, 2019). O conceito de história com o qual trabalhamos, concebe-a por suas descontinuidades e rupturas, opondo-se à ideia de uma origem e de uma continuidade linear (Foucault, 1979). Recorrer à história significa “[...] marcar a singularidade dos acontecimentos, longe de toda a finalidade monótona; empreitá-los lá onde menos se os esperava e naquilo que é tido como não possuindo história". Compreendemos, portanto, que os discursos e as práticas se engendram a partir de problemas de uma dada época, configurando gestos que se tornam habituais e difíceis de não serem reproduzidos como uma normalidadeAssim, faz-se importante percorrer, mesmo que de maneira breve, pontos fundamentais de nossa história moderna que contribuíram de maneira decisiva para a constituição dos conceitos de desenvolvimento e, posteriormente, de adolescência. A título de introdu- 
Adolescentes, Professores e Psicanalistas

ção, pontuamos que, mesmo que possamos acompanhar uma história moderna que funda suas bases na ideia de desenvolvimento, este não incidirá igualmente nos diferentes territórios, seja em relação à cisão metrópole-colônia, seja em relação à periferia-centro das cidades urbanas.

Desse modo, identificamos que ao longo dos séculos XVII, XVIII e XIX a construção do trabalho assalariado, as guerras de formação e consolidação dos Estados nacionais e o capitalismo nascente são processos não lineares que constroem novos discursos e práticas sociais. É neste contexto que Foucault (2014) identifica a formação da figura do anormal, figura para nós relevante, uma vez que orientará a concepção do normal, articulando diferentes significações médico-jurídicas ao longo do século XIX. Ao passar pelas figuras do monstro, do onanista e, finalmente, do indivíduo incorrigível, o anormal constituir-se-á em oposição à ideia de desenvolvimento apropriado, levando a psiquiatria a se consolidar como um saber que se ocuparia da infância e de suas instituições de cuidado: a família e a escola. Reforçamos a ideia de desenvolvimento como central em nossa discussão, pois ele se desdobra nas concepções sobre a infância e, posteriormente, sobre a adolescência.

Destacamos, ainda, que a lógica da normalidade-desenvolvimento não se restringirá aos corpos dos indivíduos; o conceito de desenvolvimento abarcará o intrincamento de concepções sobre o desenvolvimento da história/humanidade e sobre questões socioeconômicodesenvolvimentistas. Trata-se, assim, de um conceito que centraliza pilares estruturais do pensamento moderno.

Será, igualmente, em torno do desenvolvimento que o conceito de raça se estabelecerá como uma noção que diferencia qualitativamente distintos fenótipos. Marcas raciais que se encontram em nossa apresentação, às quais as questões adolescentes puderam nos indagar: "Nossa, você é igual à Xuxa!”. Estereótipo de mulher branca, rica e rainha dos baixinhos (foi apresentadora de programa infantil - chamava s crianças de baixinhos), a Xuxa e tudo o que ela representa têm uma história singular com os desdobramentos da noção de raça no Brasil, é em busca deles que seguiremos.

Fragmento 2 - Acordar para Poder Dormir: os pesadelos do social

O tema eram pesadelos. Um desdobramento dos medos que ocuparam alguns encontros. Ela começou a contar sobre um pesadelo que considerou horrivel: ela perdia sua sobrinha de 2 anos na rua, ficava muito triste, pois "[...] quando terei outra sobrinha loirinha como ela?".

Fruto de contingências históricas que ganham força de verdades absolutas, a raça, apesar de ser um conceito sabidamente questionável nos dias de hoje, impõe-se com toda sua força nos muitos racismos que permeiam a sociedade brasileira. São discursos que às vezes nos atravessam nos sonhos-pesadelos, mas que estavam presentes nos grupos de conversa, na medida em que as psicanalistas podem ser vistas como a Xuxa, pelas marcas, pela classe e pela raça que carregam em seus corpos.

O cotejamento de pensamento, portanto, se faz necessário. O desenvolvimento, quando relacionado à ideia de maturação do indivíduo, 
articula concepções sobre o destino biológico dos humanos, sobre raça e sobre degenerescências. Situamos, por exemplo, que foi no século XIX, no momento de uma biologia nascente, que surge a noção de raça com a qual operamos, de uma forma ou de outra, até os dias de hoje. Foi Georges Cuvier (1769-1832) quem “[...] introduziu a noção de raça articulada à hereditariedade de traços físicos comuns permanentes e bem diversos entre os grupos humanos" (Lobo, 2008, p. 193). No bojo de tal concepção, os discursos sobre origem, sobre hereditariedade e sobre as características distinguíveis ganham importância.

Ao percorrermos a história da psiquiatria infantil, deparamo-nos com o fato, apontado por Foucault (2006), de que a classificação dos anormais é anterior à ideia de desenvolvimento normal, desdobramento histórico importante por circunscrever o anormal como paradigma do normal. Esquirol é um dos primeiros médicos a organizar, no início do século XIX, uma classificação da idiotia como uma afecção mental que distingue as pessoas em relação ao seu potencial de desenvolvimento e, portanto, de educabilidade (Bercherie, 2001). Mesmo que esta não seja uma classificação própria da psiquiatria infantil, pois não existia essa especialidade, trata-se de um saber produzido sobre a infância e seus desvios, baseada na possibilidade/impossibilidade de vir a ser educado:

[Não se trata] de uma doença, [mas] de um estado no qual as faculdades intelectuais nunca se manifestam, ou não puderam desenvolver-se o bastante, para que o idiota pudesse adquirir os conhecimentos relativos à educação que recebem os indivíduos de sua idade, situados nas mesmas condições que ele (Esquirol, 1838, p. 76) ${ }^{4}$.

Sublinhamos nessa passagem, as noções de estado, de desenvolvimento e de educação, noções centrais para o que pretendemos discutir aqui, uma vez que se desdobram como um conjunto de normativas que passam a marcar as formas de ser e de conceber a adolescência, normativas diretamente vinculadas às instituições centrais para a afirmação do Estado-nacional: o trabalho, a família, a escola, o hospital e a prisão. Ademais, nas décadas de 1830-40, diretamente ligadas às repercussões do texto de Esquirol, passou-se a discriminar os idiotas e débeis para que estes fossem encaminhados aos pavilhões especiais dos hospícios, livrando os pais para trabalhar (Lobo, 2008). Assim, apesar do ensino obrigatório na França ter sido instituído em 1881, este apenas acentuou a classificação entre os normais e os anormais, uma vez que essa diferenciação já operava como um discurso basilar.

Vemos a centralidade da infância como um problema que encadeou, ao longo do século XIX, uma série de saberes e práticas que passaram a afirmar o campo médico-jurídico como normalizador da vida social, dispondo distintamente o destino das crianças ricas e das pobres. Às primeiras caberão as escolas e às segundas as instâncias de controle social: “[...] de um lado, apelo necessário à medicina; de outro, apelo necessário ao tribunal, ao juiz, à polícia, etc.” (Foucault, 2014, p. 238) - diferenciação no destino das crianças pobres e das ricas presente 
nos Estados europeus, mas que terá incidências singulares nos Estados nascentes de ex-colônias, como o caso brasileiro.

A despeito da importância em diferenciar o modo como cada Estado-nacional vai se constituindo, lembramos que a formação dessa estrutura está atrelada à natalidade, à territorialidade e ao modo de reprodução da vida e de estruturação jurídico-administrativa, instâncias que ordenarão uma sociabilidade em que as pessoas vão, paulatinamente, tornando-se sujeitos-de-direito, processo em andamento no mundo ocidental como um todo. Dessa forma, é próprio dessa transição que convivam modos díspares de socialização.

Adentramos, então, os desdobramentos do problema do anormal e suas particularidades no recém-Estado-Brasil, desdobramentos que constituem nossa história, e, como veremos, desdobram-se até os dias de hoje naquilo que identificamos em nossos fragmentos: uma interpelação da raça e da classe, que implicam modos de vidas díspares em uma mesma cidade, modos de vidas que remetem a sonhos-pesadelos.

Começamos por acentuar que, na época da Independência, grande parte da população do que passou a se chamar Brasil era escrava, situação que já nos coloca diante de problemas distintos daqueles da metrópole, mesmo que articulados a eles. Sublinhamos, mais uma vez, que os conceitos de raça, anormal e degenerescência surgem na mesma época e em vinculação direta.

Dezesseis anos após a Independência do Brasil foi fundado o Instituto Histórico e Geográfico Brasileiro (IHGB), “[...] uma das primeiras tentativas dos intelectuais do Brasil independente de agrupar elementos que pudessem ser tomados por uma identidade ou cultura nacional" (Kowalewski, 2017, p. 164). Foi encabeçado pelo IHGB a organização e difusão das bases daquilo que comporia a história do Brasil, sendo marcada desde o início por narrativas que tentavam agregar um mito fundador da nação que englobasse uma preocupação com a mistura das raças. A redação de Karl von Martius, ganhadora do concurso de como se escrever a história do Brasil, em 1845, é representativa da ideia da mestiçagem das três raças como fundadora do território nacional brasileiro, mesmo que com importâncias muito distintas entre elas (Kowalewski, 2017).

Apesar do discurso da mestiçagem ser fundador do Brasil, Kowalewski (2017) nos alerta para as contradições que operaram a partir desse discurso:

Na narrativa apresentada em suas Revistas, o Instituto relegava um espaço específico para indígenas, negros e mestiços, que não eram considerados pelos sócios como parte constitutiva da História nacional, a não ser quando o tema abordado versava sobre as mestiçagens e hibridações, fossem elas biológicas ou culturais. Esses dois grupos étnico-raciais tinham espaços desproporcionais nos artigos publicados na R. IHGB: enquanto a preocupação com os indígenas faz parte de todo o período abordado com 
grande número de artigos e debates, textos sobre negros e mestiços são uma raridade (p. 165-166, grifo nosso).

Silenciados, os africanos eram considerados estrangeiros em território nacional. Silenciamento paradoxal, pois alvo de uma grande preocupação, tal como registrada no I Congresso Internacional das $R a$ ças, em 1911, no qual João Batista Lacerda, então diretor do Museu Nacional, defenderá a teoria do branqueamento como o destino da mestiçagem no Brasil.

Ora defendida como uma política, ora silenciada como uma raça estrangeira, a mestiçagem marca a história nacional em toda a sua contradição. O mestiço, o híbrido, será, em alguns momentos, a maior singularidade do território brasileiro, a força de seu povo, e, ao mesmo tempo, uma marca de sua impureza, contradição que determina o destino dos anormais e degenerescentes.

Voltando, então, às repercussões dos discursos sobre os anormais no Brasil, ressaltamos uma questão temporal, isto é, identificamos que as práticas e discursos médico-jurídicos não tardam a chegar por aqui, porém se estabelecem de uma maneira própria, incorporando e reproduzindo as lógicas históricas de constituição do território brasileiro.

Como vimos acima, Foucault (2014) identificou na França uma diferença entre as instituições destinadas a se ocuparem das crianças de famílias pobres e de famílias ricas e, no Brasil, não foi de outra forma, porém com a singularidade de que aqui uma grande parcela da população era desconsiderada como população: os escravos-africanos, exescravos, indígenas e mestiços, amálgama que construirá repercussões singulares.

Dentro da formação do Estado brasileiro e, mais especificamente, na construção do campo educacional, fundamental na estruturação dessa forma societária, acompanhamos com Villela (2000) que a inusitada mudança da Coroa para a colônia, logo no início do século XIX, é um marco importante para a aceleração do que estava se centralizando como um sistema de educação, mas essa aceleração se deu, principalmente, no nível da educação superior, pela preocupação de formar os quadros que comporiam a burocracia estatal.

Não obstante ser uma preocupação que muito cedo criou leis e medidas constitucionais no território brasileiro, como, por exemplo, a Lei Geral de Ensino de 1827, que, segundo Villela (2000), foi a primeira lei de ensino da América Latina, tais medidas e leis operaram mais como textos escritos do que como efetivação de práticas educacionais. Ademais, durante todo o Império, as medidas de efetivação da educação nacional se centraram principalmente na formação dos professores, tendo como modelo as primeiras Escolas Normais, que ficaram sob responsabilidade dos municípios (Villela, 2000).

Sem recursos diretamente destinados à educação e sem um plano nacional, a educação básica no Brasil se formou em torno de algumas poucas Escolas Normais e de seus dirigentes, compondo um cenário muito restrito a alguns métodos de ensino e a alguns educadores, como 
Adolescentes, Professores e Psicanalistas

Benjamin Constant e Caetano de Campos, ambos do final do século XIX. Por se restringir a umas poucas escolas, o alcance da educação era limitado, atendendo, principalmente, às classes mais abastadas. Lembramos, ainda, que foi somente na Constituição de 1934 que a educação básica virou um direito. Portanto, a educação se alicerçou a partir de leis que estavam distantes das práticas cotidianas: eram poucas Escolas Normais, nas quais poucos professores se candidatavam para fazer a formação, numa dinâmica em que coexistiam outros modelos de ensino, e na qual a população sobre a qual o Estado se propunha atuar era muito menor do que a soma dos que viviam nesse território.

Identificamos como uma quebra do silenciamento das coordenadas dos conflitos na escola o grito que traz em toda a sua força a questão da diferença racial, diante de uma simples apresentação: "Nossa, vocêe é igual a Xuxa!". Grito que desvela um país fundado, pois, em contradições explícitas no que concerne a diferença entre as leis e seu funcionamento no cotidiano, e em contradições implícitas quando levamos em conta a questão da mestiçagem como aquilo que era mácula do território e sua força singular, questão relegada ao silenciamento.

Fragmento 3: a comunidade estraga

Conversando um pouco sobre o CCJ (Centro Cultural da Juventude), os adolescentes que compunham o grupo de conversa disseram frases como terem vontade de que a escola tivesse mais saídas, pois ficavam cansados de sempre estarem num prédio velho no qual tudo estava destruído. Falaram que na escola sempre tinha algo estragado. Era o último dia do grupo antes das férias - comentaram que quando voltassem todos os brinquedos estariam estragados. Tivemos dificuldade em compartilhar com eles que o ambiente era estragado, não porque ele era impecável, mas porque ele era vivo: a escola fica aberta para a comunidade, a comunidade - da qual eles também fazem parte - que fica "culpada" por estragar os brinquedos. Víamos marcas de deterioração, mas elas pareciam pequenas para concordarmos que a comunidade estraga.

Como vimos, as questões do desenvolvimento trazem em seu bojo a história do país marcado por uma delimitação racial relativa a quem ocupa o lugar de cidadania ou é relegado à condição outra, de anormal. Com esse novo fragmento, pretendemos nos aproximar das consequências subjetivas da criação de zonas de fronteira, ou seja, demarcações às vezes geográficas, às vezes econômicas, às vezes fenotípicas, às vezes de gênero, zonas que delimitam quem está dentro e quem está fora, acarretando diferentes consequências. Se a comunidade estraga, por que nós, que em alguma medida somos comunidade, não sentíamos que estava estragado e nem que poderíamos estragar? Loirinhas como a sobrinha do sonho, podíamos nos considerar parte daquela comunidade?

A composição dessas zonas está diretamente associada à formação das colônias enquanto uma territorialidade peculiar na história. Em sua argumentação sobre a necropolítica, Mbembe (2019) localiza as particularidades da formação das colônias em relação à formação dos Estados nacionais europeus, mais especificamente, à formação do Jus publicum europaeum (ordem jurídica europeia), no qual se estabeleceu 
tanto a igualdade jurídica de todos os Estados, quanto a determinação de suas fronteiras. Nessa composição, as colônias "[...] são semelhantes às fronteiras. Elas são habitadas por selvagens. As colônias não são organizadas de forma estatal e não criaram um mundo humano" (Mbembe, 2019, p. 34). Composição territorial que cria um modo específico de relação: um modo no qual está claramente demarcada a lei e a exceção, os homens e os selvagens, os de dentro e os de fora, uma racionalidade que nos concerne até os dias de hoje. Não apenas nos concerne até os dias de hoje, como opera como fronteiras dentro de territórios que foram colônias.

É nesse contexto que retornamos à discussão sobre as incidências das práticas e discursos sobre os anormais na construção do Brasil, para acrescentar que a pobreza foi entendida como um desvio da ordem, concepção que se sobrepunha à preocupação com a infância. Isto é, as crianças pobres eram condenadas às instituições assistencialistas, como estabelecimentos para indigentes e hospícios, nos quais ficavam misturadas com os adultos, instituições que funcionavam como depósitos daqueles que eram indesejados nas cidades (Lobo, 2008).

No que concerne à incorporação das diferentes classificações da idiotia, incorporou-se aqui a categoria dos estados intermediários, de modo a englobar praticamente tudo o que era considerado como desvio: a pobreza, a degenerescência das raças, o indisciplinado, as ideias políticas radicais e as mulheres que não se comportassem de acordo com a moral (Lobo, 2008). Assim, ligam-se corpo descartável, perigo social e fardo social como um modo de discriminação, combinação que seguirá operando até os dias de hoje (Lobo, 2008). Ligação que torna a identificação com a comunidade que estraga um signo de impotência: os adolescentes no grupo, que são da comunidade, identificam-se conosco, que não somos da comunidade, numa tentativa de não cair no corpo descartável, no perigo social e no fardo. Elementos que operam na cena e que, como colocamos acima, na passagem adolescente da cena familiar à cena social, podem identificar massivamente alguns no lugar do desvalor.

Esperamos ter deixado clara a correlação entre desenvolvimento, pobreza, raça e perigo social que se inaugura com a fundação do Estado brasileiro. É evidente que os desdobramentos de tal engendramento terão diversos encaminhamentos ao longo do século XX, porém nos interessa salientar a predestinação a que determinadas adolescências continuam a ser condenadas: ocupam, majoritariamente, as vagas das instituições da Assistência Social, lideram os rankings de morte violenta e encontram vagas na recém-universalizada escola que, em muitos locais, carece de condições suficientes para um ensino de qualidade.

\section{Saberes Adolescentes: adolescência como etapa do desenvolvimento e adolescência como posição no laço}

As adolescências, portanto, são distintamente marcadas em nosso tecido social: algumas implicam perigo social e resistem, ainda bem, 
Adolescentes, Professores e Psicanalistas

a serem identificadas como a comunidade que é vista como o corpo descartável, como o fardo social. Outras adolescências podem ser identificadas com o ideal de pura felicidade (Rosa, 2011), num complexo jogo em que se misturam tanto o conceito desenvolvimentista de adolescência quanto os atravessamentos de perigo social que aqui se estabeleceram.

Dentro da lógica desenvolvimentista, a adolescência é identificada como uma etapa universal, na qual as territorialidades que tentamos destacar acima são indiferentes, etapa marcada por hormônios, por mudanças corpóreas, por uma energia invejável de descobrimento do mundo e por oscilações de humor. Assim, compor-se-ia uma identidade adolescente, responsável pela futura identidade do indivíduo (Coimbra; Bocco; Nascimento, 2005). Não marcadas pelas diferenças de territorialidades e do modo distinto como são significados os estratos sociais, tais concepções individualizam e culpabilizam as subjetividades: “[...] o modo como cada um enfrenta e resolve tal fase será determinado pelo próprio indivíduo e por sua capacidade, ou falta dela, para lidar com as questões de seu desenvolvimento”.

Vemos então que o interesse pelo fenômeno da adolescência como uma etapa biológica, que inscreveria um tempo subjetivo no interior de um contexto desenvolvimentista específico, serve exatamente para desresponsabilizar o campo social de seus efeitos na construção das subjetividades.

Ao naturalizar o tempo da adolescência numa etapa do desenvolvimento biológico, acentua-se a tese de uma cisão entre social e individual; ao privilegiar os aspectos estruturais da individuação, mascaram-se as incidências do social para a construção das subjetividades. Em oposição a tais formas de compreensão da adolescência, baseadas num processo de desenvolvimento progressivo em linha reta, rumo à idade adulta, a psicanálise entende que o despertar da adolescência, como dizem Rosa e Huerta, é um trabalho psíquico necessário para “[...] uma tomada de posição do sujeito quanto a três aspectos: a sustentação da sua singularidade e sua diferença; o modo de laço que estabelecerá com a alteridade, particularmente com o Outro sexo; e quanto ao lugar que ocupará no laço social” (2020, p. 6). Desse modo, busca restituir ao adolescente toda dimensão do conflito inerente à emergência do sujeito, evidenciando as linhas de força em jogo: perda do ideal imaginário, luto e encontro com o Outro sexo.

Essa dimensão do conflito é central na teoria da sexualidade freudiana. Se Freud fez raro o uso do termo adolescência em sua obra, no entanto, inúmeras são as referências ao termo puberdade. Lembramos que o termo adolescência não fazia ainda parte do imaginário social da época de Freud. Talvez por isso ele tenha se referido ao termo apenas de forma esparsa e imprecisa no curso de sua obra, optando pelo uso corrente de puberdade. No entanto, mesmo o termo puberdade irá sofrer na obra de Freud algumas transformações de sentido, ao passar do campo do desenvolvimento biológico para adquirir a dimensão de um tempo de passagem à cena social, onde o encontro com o Outro sexo se 
atualiza e inscreve o mal-estar dos laços sociais no coração do sujeito adolescente.

Certamente a teoria freudiana da sexualidade elaborada a partir de 1905, em Três Ensaios Sobre a Teoria da Sexualidade (Freud, 2016), apontará para uma organização disposta em três etapas: autoerótica, narcísica e objetal. Se essas etapas dão conta de certo caráter progressivo da sexualidade humana, não devemos desconsiderar que o que é central para Freud é menos a dimensão desenvolvimentista, mas, sobretudo a conflitualidade pulsional que subjaz a cada etapa e os modos de resolução do conflito, sempre singulares de um sujeito a outro.

Em Freud, podemos dizer que, para o desenvolvimento da sexualidade humana, faz-se necessário um recalcamento das pulsões sexuais infantis incestuosas, e um segundo velamento posterior, na adolescência, essas mesmas moções pulsionais serão trazidas novamente à tona nessa fase do desenvolvimento, em que a maturação do corpo reativa uma grande descarga de energia sexual (pulsional), que não pode mais ser contida pelo recalcamento.

Nas palavras de Matheus (2008, p. 622),

Entende-se que a puberdade pode por vezes funcionar como elemento disparador do segundo momento da sexualidade, mas não como condição necessária. É, sobretudo, a partir do olhar do outro, ou da imagem especular que este anuncia, que surge, para o sujeito, um corpo estranho, um componente novo em seu psiquismo que não encontra registro entre os recursos simbólicos disponíveis. Esse olhar e essa imagem não estão presos à concretude da realidade, uma vez que esta é sustentada pelo campo simbólico que a fundamenta e acompanha. Da realidade, busca-se ao menos um grão que sirva de suporte para o real a ser disparado pela estranheza do olhar do outro. É por esse motivo que o momento adolescente independe imediatamente da puberdade, pois está atrelado aos sentidos que aquele corpo conquista nos laços nos quais se inscreve.

O sujeito é convocado na adolescência a ressignificar todas essas moções pulsionais que estavam adormecidas até o período de latência. Desse trabalho de atribuir um novo sentido ao sexual antes adormecido, algo permanece e resiste a significação, “[...] um resto carente de sentido - o traumático - a partir do qual o psiquismo se organiza. Esse resto diz respeito tanto ao sexual diretamente considerado, quanto às questões narcísicas que entram em cena em função dos conflitos de autoridade e poder" (Matheus, 2008, p. 622). Será esse novo velamento do real da castração que irá permitir ao adolescente ir de encontro ao Outro sexo, quando consegue suportar o trauma da castração pela via da construção de uma ficção que dê conta do sexual, do seu desejo enquanto sujeito: projeto de vida e projeto de amor. Mas para isso, para fazer a passagem da cena familiar à cena social, o adolescente precisa poder encontrar lugares possíveis de existência no socius. Lugares de pertencimento. 
Adolescentes, Professores e Psicanalistas

Nessa medida é que podemos dizer que o despertar da adolescência dá-se no (des)encontro do recém-chegado na cena social ao constatar que algumas máscaras caem. Sem tais máscaras, sedimentadas entre o discurso social e a fantasia, processa-se um movimento de desgarramento sem certezas imaginárias e a angústia diante da irrupção do real. Portanto, o processo adolescente não será apenas o despertar, mas também o trabalho de recompor, num jogo com o véu e as máscaras, uma narrativa ficcional (Rosa e Huerta, 2020).

Fragmento 4: 'é verdade que os bichos nos comem quando morremos?' No grupo de conversa, constituído por adolescentes que se voluntariaram a estar lá. Vontade que partira tanto de uma curiosidade de falar com psicólogas quanto de recomendações explícitas da equipe da escola que alguns, justamente, conversassem com psicólogas. O tema sobre o qual mais falaram naquele dia foi o medo. O horário estava quase acabando. Medo da morte, da morte de suicídio. Indagações do que acontece depois que morremos, num misto de horror e encantamento: "É verdade que os bichos nos comem quando morremos?", "É verdade que os urubus podem nos picar sem estarmos mortos?". Combinamos que esse seria o tema do próximo encontro.

Espaço para falar dos medos, dos medos da morte, morte que implica uma marca de luto. Saberes que circulam de outra forma, saberes e indagações que produziram saberes. Indagações que marcam um tempo de ruptura: entre o corpo da infância e o corpo do adulto. Poderíamos pensar que a pergunta sobre os urubus desdobrar-se-ia em perguntas sobre os urubus que comem o corpo que já tivemos? Formamos um espaço para poder falar dos medos, que no quarto fragmento se centrou no medo da morte, mas que era, também, o medo da depressão, dos cortes, do sexo. Medos que iam compondo um tema de interesse para aquele grupo que se constituiu e seguiu durante o período de um ano, com algumas oscilações.

Quando recorremos à noção psicanalítica de adolescência não estranhamos que o tema do medo da morte seja um dos primeiros a aparecer e insista ao longo dos encontros. Para a psicanálise, justamente, ser adolescente é um tempo de passagem que comporta a elaboração de lutos estruturais: dos ideais parentais da infância, das primeiras amizades, dos amores imaginados e do corpo infantil. Nesse sentido, o tempo da adolescência pode ser considerado como um tempo de conclusão, o que, em parte, poderia explicar certa prevalência de temáticas de vida e morte no discurso e nos modos de passagem ao ato adolescente.

Como nos aponta Freud (2010), em Luto e Melancolia, dois destinos se anunciam para o ego quando confrontado ao imperativo do abandono dos primeiros objetos de amor, vítima do interdito do incesto. Um dos destinos possíveis seria o sujeito adolescente seguir o caminho 'normal' do abandono do objeto, acatando o doloroso sofrimento implicado no luto e contentando-se com outros objetos do mundo social. Outra possibilidade seria recusar a substituição do objeto, caindo numa cilada melancólica.

Podemos relacionar a entrada do adolescente na cena social a um processo entre luto e melancolia, que implica em perder o lugar 
no ideal parental para lançar-se na busca de um lugar no campo social no qual poderá constituir-se como sujeito no jogo identificatório e da escolha objetal. Esse processo pode se dar como passagem ou como fixação; como luto ou como melancolia. No caso de ser uma passagem, se trata de constituir um ideal do ego rumo à escolha objetal. No caso da fixação melancólica, o investimento objetal fixa-se a uma identificação e o próprio ego será investido como objeto, de amor ou de desamor.

Para finalizar esta parte, recorremos, mais uma vez, ao nosso quarto fragmento: como foram escolhidos os estudantes dos grupos de conversa? A despeito da proposta de ser uma escolha voluntária, sabemos - e pudemos conversar com a coordenação a respeito dessa escolha - que o fato de sermos psicólogas fez com que os adultos - pais, coordenadores e professores - convocassem alguns estudantes para dali participar, aqueles que são julgados mais subversivos, mais desviantes, e, poderíamos dizer, mais questionadores?

Afirmamos a juventude como um momento indagador: "[...] inquieta-se, não se conforma facilmente com a quebra das promessas da infância de ter um lugar relevante na estrutura social" (Rosa, 2011, p. 8). Assim, na passagem da cena familiar à cena social, questionamentos poder ser produzidos pelos adolescentes; os adultos, que ocupam o ideal de maioridade, são questionados por suas fragilidades e incompletudes. Cabe aos adultos escutar os adolescentes no difícil exercício de construção de conflitos e saberes, ao invés de tomas as suas indagações como falas efêmeras de adolescentes e, dessa forma, calar o seu processo.

Caminhamos, então, para o $3^{\circ}$ tempo deste artigo, isto é, o tempo de construção do conflito. Apontamos como aquilo que se elaborou no grupo de conversa sobre a morte, sobre o desvio e sobre a adolescência, pedia passagem para interpelar a equipe como um saber que dizia respeito a todos daquela instituição. Saber produzido no grupo, mas que já atravessava as aulas, os passeios e os intervalos. Saber que contava de uma posição: a importância dos conflitos não se reduzirem ao corpo de alguns, produzindo o medo da morte, a identificação com lugares despotencializados e subalternos.

\title{
$3^{\circ}$ Tempo - Efeitos Adolescentes: a possibilidade de construção do conflito institucional
}

\begin{abstract}
Fragmento 5: Banheiro
Depois de um ano de grupo de conversa, composto, praticamente, com os mesmos adolescentes, construímos junto com a coordenação uma reunião com todos os professores da escola para apresentar a importância dos conflitos, a ser conduzida pela Prof ${ }^{a}$ Dr $^{a}$ Maria Cristina Vicentin, uma pesquisadora e professora universitária de nossa referência. Nesse encontro, com a equipe da escola inteira reunida, os professores socializaram títulos de cenas de conflitos vividas por eles com os estudantes. Era a vez do título 'Banheiro': o professor de matemática, que havia dado esse título a sua cena, iniciou pontuando que ela não tinha sido vivida naquela instituição, era uma cena antiga. Descreveu uma aula muito difícil e ruidosa. Um aluno, o
\end{abstract}


Adolescentes, Professores e Psicanalistas

mais engraçadinho da turma, pergunta se pode ir ao banheiro no meio do tumulto. Com essa pergunta, o professor nos diz que perdeu a cabeça. Enfatiza para nós, que se sentiu péssimo, sentiu que perdeu algo, que fracassou.

Partindo da discussão por nós proposta nesse artigo, esperamos ter deixado claro as linhas orientadoras do que propomos como intervenção clinicopolítica em escolas: a importância de sustentar a ética do analista na escuta institucional, isto é, na construção de um saber que parte dos adolescentes, mas que retorna para a equipe. Quando aberta a escuta, os profissionais, também, podem operar com esses saberes, demonstrando que estes se encontram nas malhas discursivas compartilhadas. O conflito, a cena, elegida por esse professor, recolhe cirurgicamente os elementos que tentamos trabalhar neste artigo: a escola representada pela sala de aula; o desvio, representado pelo aluno engraçadinho; e o endereçamento ao grupo, do qual nós fazíamos parte, que representa a possibilidade de sustentação do conflito como uma questão coletiva e não individual.

Cenas conflitivas que, na maioria das vezes, são tratadas como fracassos individuais, fracassos, que como pretendemos ter demonstrado, remontam uma história: a história do conflito e a história de como nos tornamos o que somos. Por que as cenas conflitivas são vividas como um fracasso individual?

Resposta, que se possível de ser dada, precisaria levar em conta a crueldade de vivermos num sistema, o capitalista, no qual a destituição de nossa posição está em jogo o tempo todo, evidentemente, para alguns mais do que para outros. Dessa forma, construir o conflito significa localizá-lo e endereçá-lo ao coletivo. Daí a importância de retornar às equipes os saberes que os adolescentes produzem:

\begin{abstract}
A impactante presença dos adolescentes fazendo da escola um campo de 'ocupação' e de 'extensão' de seus territórios existenciais sugere que os corpos dos adolescentes protagonizem modos de ser e formas de resistência frente à cultura escolar, quando transpõem ou deslocam limites, configurando novos espaços de expressão e importantes campos de disputa pela construção de sentidos coletivos. Evidencia, também, que a escola pode ser espaco de acolhida e experiência desse deslocamento de fronteiras ( $\mathrm{Vi}$ centin; Gramkow, p. 381).
\end{abstract}

Afirmamos que é no campo compartilhado que o sujeito faz a experiência de inventar-se e inventar o mundo (Rosa, 2016), ampliando os sentidos das investigações e dos ensaios, atrelando-os ao pressuposto de que toda ação é uma ação política.

Retomemos, por fim, nosso percurso. Partimos de uma asserção produtora de um estranhamento-familiar: "Nossa, você é igual a Xuxa!", pergunta dura e fundamental, pois deflagradora dos lugares sociais que estavam colocados. Práticas e discursos constituídos em uma história que nos ultrapassava e se reatulizava nesse encontro: psicólogas brancas e estudantes negras. Se tivéssemos parado no incômodo, calaríamos isso que se opera como um conflito dentro de nós: o gesto fácil 
talvez fosse não nomear a diferença, mas ela grita na voz da estudante e em nossa cabeça, em busca de um lugar possível no pensamento e, sobretudo, na instituição.

Porém, esse era o tempo de apresentação, precisariam vir todos os outros para que o conflito pudesse pedir passagem e ganhar lugar. Orientadas pela ética e política da psicanálise, pudemos escutar aquilo que nos era dito e dar estatuto de saber ao que estava sendo formulado. Como num ensaio, tentamos não parar na clássica divisão entre sujeito e objeto que opera em qualquer pesquisa. Mesmo sabendo que se trata de um limite para o pensamento moderno, tentamos ir recolhendo fragmentos que juntos demonstram a fragmentariedade de nossas reflexões, a contingência de nossos hábitos e a urgência de poder criar outras linhas de força: poder começar por ser a Xuxa, para então, ser outra coisa, assim como cumprir nossa (escola, saúde mental, família) função de interpelar e acompanhar o adolescente em sua construção singular, a fim de que ele se permita, por um lado, um exercício de sua erótica e, por outro, afirmar-se em um laço discursivo em que possa, ao contar sua própria história, também narrar a história de seu tempo, a contrapelo da história oficial, iluminando o escuro dos laços em jogo.

Recebido em 12 de novembro de 2020 Aprovado em 24 de fevereiro de 2021

\section{Notas}

1 O PSOPOL (Laboratório Psicanálise, Sociedade e Política/IP-USP) produz pesquisas sobre a adolescência e a educação. Conferir, particularmente, os trabalhos de Ana Paula Musatti-Braga, Cristina Rocha e de Viviani CarmoHuerta.

2 Destacamos que a abertura e a parceria da equipe dessa escola foram fundamentais para que elaborássemos nossas ideias. Ressaltamos, ainda, que a construção coletiva, uma marca dessa instituição, foi o que pôde criar o espaço para nossas elaborações.

3 Todos os Fragmentos aqui discutidos foram recortados dos grupos de conversa coordenados pelas psicanalistas e pesquisadoras: Arieli Maciel Palácio Alvarez e Joana Sampaio Primo.

4 N'est pas une maladie, c'est un état dans lequel les facultés intellectuelles ne se sont jamais manifestées, ou n'ont pu se développer assez pour que l'idiot ait pu acquérirles connaissances relatives a léducation que reçoivanent les individus de son age.

\section{Referências}

ADORNO, Theodor Wiesengrund. O Ensaio como Forma. Tradução de Jorge de Almeida. In: ADORNO, Theodor Wiesengrund. Notas de Literatura I. São Paulo: Editora 34, 2012. P. 15-45.

BERCHERIE, Paul. A Clínica Psiquiátrica da Criança: estudo histórico. Tradução de Oscar Cirino. In: CIRINO, Oscar. Psicanálise e Psiquiatria com Crianças: desenvolvimento ou estrutura. Belo Horizonte: Autêntica, 2001. P. 127-144. 
Adolescentes, Professores e Psicanalistas

CATROLI, Viviani Sousa do Carmo; ROSA, Miriam Debieux. O Laço Social na Adolescência: a Violência como Ficção de uma Vida Desqualificada. Estilos da Clínica, São Paulo, v. 18, n. 2, p. 297-317, ago. 2013. Disponível em: <https:// www.revistas.usp.br/estic/issue/view/6146>. Acesso em: 12 out. 2020.

COIMBRA, Cecília; BOCCO, Fernanda; NASCIMENTO, Maria Lívia do. Subvertendo o Conceito de Adolescência. Arquivos Brasileiros de Psicologia, Rio de Janeiro, v. 57, n. 1, p. 2-11, 2005. Disponível em: <http://pepsic.bvsalud.org/pdf/ arbp/v57n1/v57nla02.pdf >. Acesso em: 13 out. 2020.

ESQUIROL, Etienne. Des Maladies Mentales - considerees sous les rapports medical, hygiénque et médico-légal. Brexelles: Librairie Médicale et scientifique de J.B. Tircher, 1838.

FOUCAULT, Michel. Nietzsche, a Genealogia e a História. Tradução de Roberto Machado. In: FOUCAULT, Michel. A Microfísica do Poder. Rio de Janeiro: Graal, 1979. P. 15-37.

FOUCAULT, Michel. O que São as Luzes?. In: FOUCAULT, Michel. Tradução de Elisa Monteiro. Arqueologia das Ciências e História dos Sistemas de Pensamento (Ditos e Escritos II). Rio de Janeiro: Forense Universitária, 2000. P. 364-365.

FOUCAULT, Michel. A Ordem do Discurso. Tradução de Laura Fraga de Almeida Sampaio. São Paulo: Edições Loyola, 2001.

FOUCAULT, Michel. O Poder Psiquiátrico: curso dado no Collège de France (1973-74). Tradução de Eduardo Brandão. São Paulo: Martins Fontes, 2006.

FOUCAULT, Michel. É Importante Pensar? Tradução de Ana Lúcia Paranhos Pessoa. In: FOUCAULT, Michel. Ditos e Escritos VI. Rio de Janeiro: Forense Universitária, 2010. P. 354-358.

FOUCAULT, Michel. Os Anormais: curso dado no Collège de France (1974-1975). Tradução de Eduardo Brandão. São Paulo: Martins Fontes, 2014.

FREUD, Sigmund. Luto e Melancolia. Tradução de Paulo César de Souza. In: FREUD, Sigmund. Obras Completas. v. 12. São Paulo: Companhia das Letras, 2010. P. 170-194. [1917-1915]

FREUD, Sigmund. Três Ensaios da Sexualidade. Tradução de Paulo César de Souza. In: FREUD, Sigmund. Obras Completas, vol. 6. São Paulo: Companhia das Letras, 2016. P. 13-172. [1905]

FREUD, Sigmund. A Cisão do Eu no Processo de Defesa. Tradução de Paulo César de Souza. In: FREUD, Sigmund. Obras Completas. v. 19. São Paulo: Companhia das Letras, 2018. P. 345-350. [1940]

KOWALEWSKI, Daniele. Experiência-Brasil: diversidade, diferenças, educação. In: SETTON, Maria da Graça Jacintho et al. (Org.). Mérito, Desigualdades e Diferenças: cenários de (in)justiça escolar no Brasil e em Portugal. Alfenas: Editora Universidade Federal de Alfenas, 2017. p. 160-177.

LACAN, Jacques. O Seminário - Livro 17: O Avesso da Psicanálise. Tradução de Ari Roitman. Rio de Janeiro: Zahar, 1992. [1969-70]

LACAN, Jacques. O Tempo Lógico e a Asserção de Certeza Antecipada. Tradução de Vera Ribeiro. In: LACAN, Jacques. Escritos. Rio de Janeiro: Jorge Zahar, 1998. P. 197-213.

LOBO, Lilia Ferreira. Os Infames da História: pobres, escravos e deficientes no Brasil. Rio de Janeiro: Lamparina, 2008.

MATHEUS, Tiago Corbisier. Quando a Adolescência Não Depende da Puberdade. Revista Latinoamericana de Psicopatologia Fundamental. São Paulo, 
v. 11, n. 4, p. 616-625, dec. 2008. Disponível em: <http://www.scielo.br/scielo.php?script=sci_arttext\&pid=S1415-47142008000400008\&lng=en\&nrm=iso $>$. Acesso em: 12 out. 2020.

MBEMBE, Achille. Necropolítica: biopoder, soberania, estado de exceção, política da morte. Tradução de Renata Santini. São Paulo: N-1 edições, 2019.

PRIMO, Joana Sampaio; ROSA, Miriam Debieux. Fronteiras Invisíveis: alteridades e lugares discursivos. Rondônia, UNIR, Culturas \& Fronteiras, v. 1, n. 1, p. 24-42, 2019. Disponível em: <https://www.periodicos.unir.br/index.php/culturaefronteiras/article/view/4475/pdf>. Acesso em: 12 out. 2020.

ROSA, Miriam Debieux. Adolescência: da Cena Familiar à Cena Social. Psicol. USP, São Paulo, v. 13, n. 2, p. 227-241, 2002. Disponível em: <http://www.scielo. $\mathrm{br} /$ scielo.php?script=sci_arttext\&pid=S010365642002000200013\&lng=en\&nrm =iso $>$. Acesso em: 12 out. 2020.

ROSA, Miriam Debieux. O Jovem e o Adolescente na Cena Social: a relação identificação, ato e inserção no grupo social. In: BIASOTO JUNIOR, Geraldo; SILVA, Luiz Antonio Palma e (Org.). Políticas Públicas em Questão. São Paulo: FUNDAP, 2011. P. 214-230.

ROSA, Miriam Debieux. A Clínica Psicanalítica em Face da Dimensão Sociopolítica do Sofrimento. São Paulo: Escuta, 2016.

ROSA, Miriam Debieux; FERREIRA, Mariana Belluzi; SOUZA, Priscilla Santos; VICENTIN, M.C.G. Os trabalhadores do social e os impasses Frente Às Demandas da Adolescência: política e singularidade. In: GURSKI, Rose et al. (Orgs.). Quando a Psicanálise Escuta a Socioeducação. v. 1. Belo Horizonte, 2019. P. 3152.

ROSA, Miriam Debieux; CARMO-HUERTA, Viviane. O Que Resta da Adolescência: despertar nas fronteiras e nos fronts. Estilos da Clínica, São Paulo, v. 25, n. 1, p. 5-20, 2020. Disponível em: <http://www.revistas.usp.br/estic/article/ view/167681>. Acesso em: 21 out. 2020.

SOUSA, Edson Luiz André. A Vida entre Parênteses: o caso clínico como ficção. Psicologia Clínica, Rio de Janeiro, v. 12, n. 1, p. 11-19, 2000.

VICENTIN, Maria Cristina Gonçalves; GRAMKOW, Gabriela. Pistas para um Agir Criançável nas Experiências de Conflito. ETD - Educação Temática Digital, v. 20, n. 2, p. 368-390, 11 abr. 2018.

VILLELA, Heloísa de Oliveira Santos. O Mestre-Escola e a Professora. In: LOPES, Eliane Marta Teixeira; FARIA FILHO, Luciano Mendes; VEIGA, Cynthia Greive (Org.). 500 Anos de Educação no Brasil. Belo Horizonte: Editora Autêntica, 2000. P. 95-134.

Joana Sampaio Primo é psicanalista, Pesquisadora do Laboratório psicanálise sociedade e política (PSOPOL-IP/USP); Doutoranda do Programa de Psicologia Clínica, IPUSP. Supervisora do braço Educação do Grupo Veredas: psicanálise e imigração do IP-USP. Bolsista FAPESP, No do processo: 2019/12316-9.

ORCID: http://orcid.org/0000-0001-7802-4094

E-mail: joanaprimo@gmail.com

Miriam Debieux Rosa é psicanalista, Professora Titular do Instituto de Psicologia da USP. Coordena o Laboratório Psicanálise, Sociedade e Politica 
(PSOPOL) e o Grupo Veredas: psicanálise e imigração. Presidente da Rede Interamericana de Psicanálise e Política (REDIPPOL).

ORCID: http://orcid.org/0000-0002-9518-0424

E-mail: debieux@terra.com.br

Viviani Carmo-Huerta é psicanalista; ATER - Attaché Temporaire d'enseignement et de recherche Laboratoire CLInique PSYchanalyse Developpement (CLIPSYD EA 4430) Université Paris Ouest Nanterre La Defense. ORCID: http://orcid.org/0000-0002-4914-0448

E-mail:vivianisc@gmail.com

Editora-Responsável: Fabiana de Amorim Marcello

Este é um artigo de acesso aberto distribuído sob os termos de uma Licença Creative Commons Atribuição 4.0 Internacional. Disponível em: <http:// creativecommons.org/licenses/by/4.0>. 